\title{
Education for Digitization: A Case Studyon Sharing E-Information Resources inUniversity Library
}

\author{
Li-hong Zhu \\ Library of Huazhong Normal University, \\ Wuhan, Hubei 430079 , P.R.China \\ E-mail:zlh_lib@mail.ccnu.edu.cn
}

\begin{abstract}
This paper reported an international survey of library, information science (LIS), computer science faculty and websites, regarding digital libraries courses and curriculum at our institutions. We concluded that few universities currently offer courses on digital libraries while many universities have not developed Digital Library (DL) courses, even they are aware of the need to develop curriculum in this growing area of research and practice. The major aim of the paper is to present results from a survey on the current state of digital library education (DLE) in academic institutions. Additionally we examine the rationale and orientation for digital library education. We suggest several models that have emerged in the teaching of DLE and in incorporation of relevant topics into various curricula.
\end{abstract}

\section{Introduction}

Information, especially digital information, is becoming an increasingly important component of modern life. More and more individuals rely upon the Internet for routine information gathering. It is particularly important for students: 88.4 percent of entering 2002 full-time freshmen reported using the Internet for homework during the year prior to beginning college, as compared with 84.5 percent in the fall of 2006[1]. Naturally, librarians are playing essential roles in making electronic information resources and services more widely available to the public.

Digital libraries (DLs) are emerging as an important area of research and education for information science, computer science and a number of other related disciplines. In this paper, our discussion is based on a recent worldwide survey of DL courses. What we conclude from our analysis is the urgent need for the development of DL education programs amidst a burgeoning growth of DL research and practice by librarians, and information and computer scientists.

Please use the following format when citing this chapter:

Zhu, L.-H., 2007, in IFIP International Federation for Information Processing, Volume 252, Integration and Innovation Orient to L-Society Volume 2, eds. Wang, W., (Boston: Springer), pp. 429-436. 
Today's libraries are facing with the challenges of integrating traditional and emerging formats, balancing resource allocation between traditional and upcoming technologies and building new information management processes and procedures. As intermediaries between the challenging, multi-format, multi-media information domain and the ever demanding user community, librarians need to be proactive and concerned about the new information landscape. The four distinct categories of information discussed are popular information, scholarly information, digitization projects and Web resources. 'Popular information' is more or less trade and commercial in nature which comprises the print book and its electronic counterpart, the emerging print-on-demand (POD), journals and newspapers (print and online), and the audio/visual media (analogue and digital). The 'scholarly information' is academic and scientific in nature and consists of the print and electronic books, journals, scholarly articles, theses and dissertations, course management materials and e-print archives[2]. The 'digitization projects' mainly concern themselves with the vast number of worldwide initiatives on commercial, national, state and local digital library projects.

Digital libraries in China are seen as the systematic engineering of crossinstitutions, professions, disciplines and regional boundaries. The Government realizes the importance of digital libraries in serving the country's goals. The construction of the national digital library is prioritized as one important component of its new national information infrastructure. Government departments involved include the Ministries of Culture, Education, Science and Technology, Finance, Communications, Information Industry, and the State Development and Planning Commission, among others.

Another characteristic of the Chinese digital libraries is the collaboration between government agencies and professional institutions/associations. China Digital Library was brought under the control of the Department of Ministry. It was also the key project, "Project 863 " of the State Council. Tsinghua University Digital Library was sponsored by the Ministry of Education. National Technological Library and The practical collaborative applications of the China Digital Library have advanced communications, information and knowledge power in the developing world. For example, In recent years, the storage capability of digital databases in HNUL(Huazhong Normal University Library ) has greatly expanded and Multimedia resource has reached $1.5 \mathrm{~TB}, 7050$ online E-books are subscribed. 43 Chinese and foreign language databases legally connected with HNUL have covered all main disciplines in HNU campus. Among them, there are 19 Chinese databases, 14 foreign ones, 8 trial databases, and 2 special databases created by its staff members of HNUL. The E-journal and E-book databases are popular with all kinds of patrons for their convenience. Besides the commercial databases, HNUL has been developing its own databases, "The database of Issues in the rural area of China" and "The database of thesis by HNU graduates" which are branches of China Academic Library \& Information System (CALIS).This paper concentrated on the education for digital libraries such as interpretation of digital library, essential educational context, as well as perspective for choices and orientation. Classic educational questions regarding digital libraries arise in many institutions including:

What is the meaning of "digital library education"?

Which kinds of courses do we teach about in digital library?

How to teach the users in DL? 


\section{DLE Review}

What is a "digital library"? The answer is not self-evident. Digital library as a concept and a reality is defined in a number of ways; at times it is even treated as a primitive, undefined concept. In other words, there is no agreed upon definition of digital libraries. We will reflect more about this in the review of definitions in the next section[3][4]. Currently, there is little systematic support for developing DL courses and curricula, and no coordinated effort in library and information science (LIS) or computer science to provide DL education. At present, we do not know much about good digital library education. We do not know what knowledge is required to produce information or computer professionals to work as digital librarians, digital developers, or in other job categories, or even what the job designations or requirements will be in the future. Computer scientists may be responsible for the technical development of digital libraries, with information scientists focusing on the content, organization, users, and retrieval of information. But just a decade later, by the start of 2000 s, research, practical developments, and general interest in digital libraries has exploded globally. What a decade for digital libraries!

The emerging demand for digital librarians and digital libraries may warrant the restructuring of the library and information science, and the computer science curricula. In the United States, several universities have reorganized existing library schools to emphasize digital information and online services. Two notable examples are at Berkeley and Michigan. In addition, there are numerous specialized courses, ranging from creating web sites for computer scientists to seminars on intellectual property for lawyers. Nevertheless, the number of courses that are specifically on digital libraries is surprisingly small[5].

Several trends affected this digital library explosion.

First, advanced societies in the Western world kept evolving into a new form variously referred to as information, knowledge, or post-industrial society. Managing knowledge records became an ever more important part and problem of that evolving society, especially since the phenomenon of information explosion, the unabated growth of knowledge records of all kinds, kept accelerating.

Second, the digital and networked technology reached a certain level of maturity and spread rapidly, which provided for more involved, varied, and broader opportunities and problems at the same time.

Third, in most, if not all fields, the nature of scholarly communication changed drastically, creating problems and fueling exploration for new approaches for supporting and sustaining it.

Finally, substantive funding became available for research and for practical developments and explorations on a variety of solutions to these problems. Digital libraries have been embraced as one (but not the only one) of the more advanced and more encompassing conceptual and practical solutions.

The digital library education questions, we concern about teaching in such kind of these educational areas, and resolve the question the contents and methods of digital library education $A$ scheduling instance consists of a set of $n$ jobs $V=\{1,2, \ldots, n\}$. With each job $\mathrm{j} \in \mathrm{V}$ we associate a (strictly) positive processing time pj and a non-negative weight $\omega \mathrm{j}$. In addition to the jobs, a number $\mathrm{m}$ of identical parallel machines will be given. The machines all run with the same speed and can process any job. Of course, at any point in time, each machine can process only one job and 
every job can only be processed by one machine. We will restrict to the nonpreemptive case. Once a job is started on a certain machine, it will be finished on that machine without any interruption.

\section{DLE Project}

\subsection{What kinds of course $s$ do we teach about in digital library}

The answer depends, to a large extent, on having a relatively clear idea about what are digital libraries. As mentioned, no agreed upon definition exists, which is fine, because the same constructs can be viewed from a number of viewpoints or perspectives. Let us explore some of these perspectives through definitions offered. Of course, a choice of a given perspective dictates the choice of the content.

Different perspectives about digital libraries, together with competing visions and associated definitions, come from several communities that are involved in digital library work. We are concentrating here on two communities: research and practice. While they work and proceed independently of each other, they can be considered on two ends of a spectrum, which as yet have not met in the middle. To use another metaphor: the research and practice communities are in the same planetary system, but one is on Mars, the other on Venus. The research community grounded mostly in computer science, on one end of the spectrum, asks research questions directed toward future vision or visions of digital libraries, or rather of their various technology oriented aspects and components, unrestricted by practice. On the other end of the spectrum, the practice community, grounded mostly in librarianship and information science, asks developmental, operational, and use questions in real-life economic and institutional contexts, restrictions, and possibilities, concentrating on applications on the use end of the spectrum.

In research, DLIs did not define 'digital library.' In order to incorporate a wide range of possible approaches and domains, the concept is treated broadly and vaguely. Thus, the projects, particularly in DLE, cover a wide range of topics, stretching the possible meaning of digital library to and even beyond the limit of what can be considered as being digital and at the same time recognizable as any kind of a library or a part thereof. This is perfectly acceptable for research -- frontiers need to be stretched. But at the same time, it makes choices for educational content diffuse and difficult.

Digital libraries are organizations that provide the resources, including the specialized staff, to select, structure, offer intellectual access to, interpret, distribute, preserve the integrity of, and ensure the persistence over time of collections of digital works so that they are readily and economically available for use by a defined community or set of communities.

\subsection{Toward of Model of DLE}

At this point in time, it is premature to suggest a fully developed curriculum, including courses, for digital library education. However, following the model of the $\mathrm{ACM}$ in their development of an undergraduate curriculum in Information Studies, 
we can suggest several curriculum areas and substantive topics that seem to be important in the further development and incorporation of digital libraries education into LIS. If we are to succeed in developing effective models for digital libraries education, we need to fashion a hybrid curriculum that brings together the complementary strengths from diverse departments such as computer science, psychology, policy studies, and library and information studies. Such interdisciplinary partnerships, while not new, often prove to be problematic in their implementation.

Our personal position is that digital libraries are first and foremost libraries, and, as such, any model curriculum should maintain a core set of courses that address the major functions and activities of libraries in general, in both digital and traditional forms. At the same time, courses explicitly focusing on technology for digital libraries should strive to connect specific technical applications to the library environment. Our suggested list of curriculum areas for digital libraries education takes into account the need for interdisciplinary collaboration.

Table1. Curriculum Areas and Suggested Topics for Digital Library Education

\begin{tabular}{l|l}
\hline \multicolumn{1}{c|}{ CURRICULUM AREAS: } & \multicolumn{1}{|c}{ TOPICS: } \\
\hline $\begin{array}{l}\text { Theoretical and Historical } \\
\text { Foundations }\end{array}$ & $\begin{array}{l}\text { History of libraries; Human information behavior; } \\
\text { Information retrieval theory; Development of digital } \\
\text { collections and digital libraries }\end{array}$ \\
\hline $\begin{array}{l}\text { Technical Infrastructure of the } \\
\text { Digital Library }\end{array}$ & $\begin{array}{l}\text { Information retrieval engines; Database construction of } \\
\text { digital libraries; Distributed collections; Multimedia } \\
\text { formats and applications; Interoperability }\end{array}$ \\
\hline $\begin{array}{l}\text { Knowledge Organization in } \\
\text { Digital Libraries }\end{array}$ & $\begin{array}{l}\text { Metadata; Indexing; Classification; Database integration; } \\
\text { Document formats }\end{array}$ \\
\hline $\begin{array}{l}\text { Collection Development and } \\
\text { Maintenance }\end{array}$ & $\begin{array}{l}\text { Digital archives; Digital conversion technology; Digital } \\
\text { preservation }\end{array}$ \\
\hline $\begin{array}{l}\text { Information Access and } \\
\text { Utilization of Digital Libraries }\end{array}$ & $\begin{array}{l}\text { Users and uses of digital libraries; Usability and evaluation } \\
\text { research; Information behavior in digital libraries }\end{array}$ \\
\hline $\begin{array}{l}\text { Social, Economic and Policy } \\
\text { Issues }\end{array}$ & $\begin{array}{l}\text { Electronic publishing; Scholarly communication; } \\
\text { Copyright issues and intellectual property rights in digital } \\
\text { libraries }\end{array}$ \\
\hline Professional Issues & $\begin{array}{l}\text { Roles and responsibilities of the digital librarian; } \\
\text { Management of digital libraries; Bibliographic instruction }\end{array}$ \\
\hline
\end{tabular}

\section{Training to use the Digital Resources in DL}

University libraries are faced with the challenges of integrating traditional and emerging formats, balancing resource allocation between traditional and upcoming technologies and building new information management processes and procedures. Libraries today buy, subscribe, license and accumulate information in an unprecedented array of content categories or publication types, and in a rapidly proliferating mix of formats (digital as well as print).

As intermediaries between the challenging, multi-format, multi-media information domain and the ever demanding user community, DLE need to be proactive and concerned about the new information landscape. The four distinct 
categories of information discussed are popular information, scholarly information, digitization projects and Web resources. 'Popular information' is more or less trade and commercial in nature which comprises the print book and its electronic counterpart, the emerging print-on-demand (POD), journals and newspapers (print and online), and the audio/visual media (analogue and digital). The 'scholarly information' is academic and scientific in nature and consists of the print and electronic books, journals, scholarly articles, theses and dissertations, course management materials and e-print archives. The 'digitization projects' mainly concern themselves with the vast number of worldwide initiatives on commercial, national, state and local digital library projects. The 'Web resources' form an important stakeholder in the new genre of information resources, providing an array of challenges as well as opportunities to the information professional. The information available in the Web (WWW) could be categorized as surface Web (visible Web) resources and the deep Web (invisible Web) resources.

As the new information landscape, the DLE need to reform to profile of user behavior, and must teach use of electronic information services (EIS), information skills, and the role of training and wider learning experiences in DL. DLE training project for user is including three aspects as follows.

\subsection{Teaching users to known DL architecture in university library}

A digital library is a complicated systematic engineering. It covers telecommunication infrastructure, computer hardware support systems, information

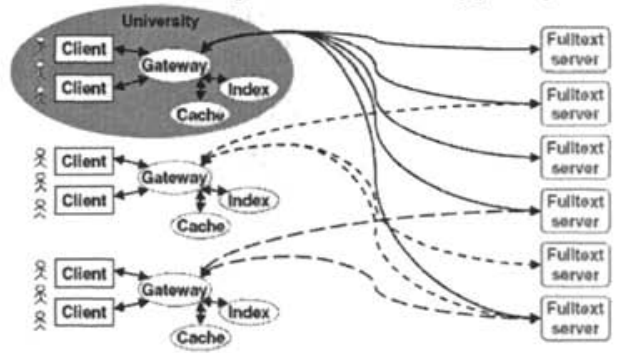

Fig. 1. Distributed Digital Library Architecture

retrieval, digital information processing, digital information storage, digital information exchange, digital information organization, and interface design from the technique perspective. The World Wide Web has changed the way research literature is accessed. Most publishers put their fulltext archive onto the web as DL containing downloadable files in the portable document format (PDF). Integrating multiple indexes of bibliographic data about the accessible documents into a single DL portal allows users to search all archives simultaneously. The result is the DL architecture shown in Figure. 1.

\subsection{Teaching users to use CALIS information resources in university library}

The China Academic Library \& Information System (CALIS) is one of the two public service systems planned by the Chinese Higher Education Schema "211 
Program" authorized by the State Council of China. CALIS organized the indexes/abstract (I/A) titles included Ei Village, Web of Science, INSPEC, Cambridge Science Abstracts (CSA), OCLC's First Search, ProQuest Digital Dissertations, BIOSIS Previews (BP), Current Contents, Chemistry Server, Derwent Innovation Index, Journal Citation Reports on the Web(JCR), CA on CD, and National Technical Information Service (NTIS), Full-text products included ScienceDirect OnSite, IEE/IEEE Electronic Library (IEL), International Digital Electronic Access Library (IDEAL), Springer-LINK, Kluwer Online, Academic Search Elite, Business Source Premier, ABI/TNFORM Global, Academic Research Library, IOPP, Science Online, and Nature etc.

The duty of DLE is known to be able to render both active and individualized services to its users in imparting the knowledge and transmitting information. By means of literature service network, we can convey the information from periodicals and dissertations to readers, which will enable readers to share information embodied, And, we will collect the relevant information with regard to the latest publications, which will be sent to readers on the regular basis so as to enable readers to obtain information from various databases. Besides, we have also set such special columns as "Specific Information about Books" and "Online Consultation Activity".

\subsection{Teaching users to use information retrieval system in university library}

The content/information integration model adopted for the system is illustrated in Figure. 2. Information retrieval in the library portal has been made as user friendly as possible so that even people with less or no computer and Web background can get the best out of the vast treasure of information resources available at HNU.

Hyperlink buttons are provided for each and every significant information source or publication type. Simple pop-up and pull-down menus appear as and when these links are clicked. Users can select the service of their choice based on context relevance such as the library specific information and library rules/regulations, DL OF HNU onsite full-text /abstract/index databases, e-journals, online services such as Web-based databases (scholarly as well as corporate) and value added information products, popular and useful hyperlinks, online reference queries, Frequently Asked Questions (FAQs) on library services/activities, etc.

The Library Portal interface frame is shown in Figure. 3. DL do enable the creation of local content, strengthening the mechanisms and capacity of the library's information systems and services. They increase the portability, efficiency of access, flexibility, availability and preservation of content. Value added and pinpointed information at the click of the mouse has become a reality at DL of HNU and the library portal is now giving access to the invaluable collection hosted by the DL.

\section{Conclusions and Further Research}

An aggregated and integrated approach to the complex, yet challenging information education strategies to be adopted and practiced by the libraries for the 21 st century is illustrated in this paper. Our state-of-the-art analysis of DL education, worldwide, was an initial foray into an important and expanding area of investigation. Ongoing 
research is required on a larger scale to gather data from every university of LIS and computer science in order to update and extend our findings. We need to develop good models of DL educational programs and courses, and a greater synergy between DL research and education. Finally, we need the resources to develop and sustain an expanding and far reaching program of DL education.

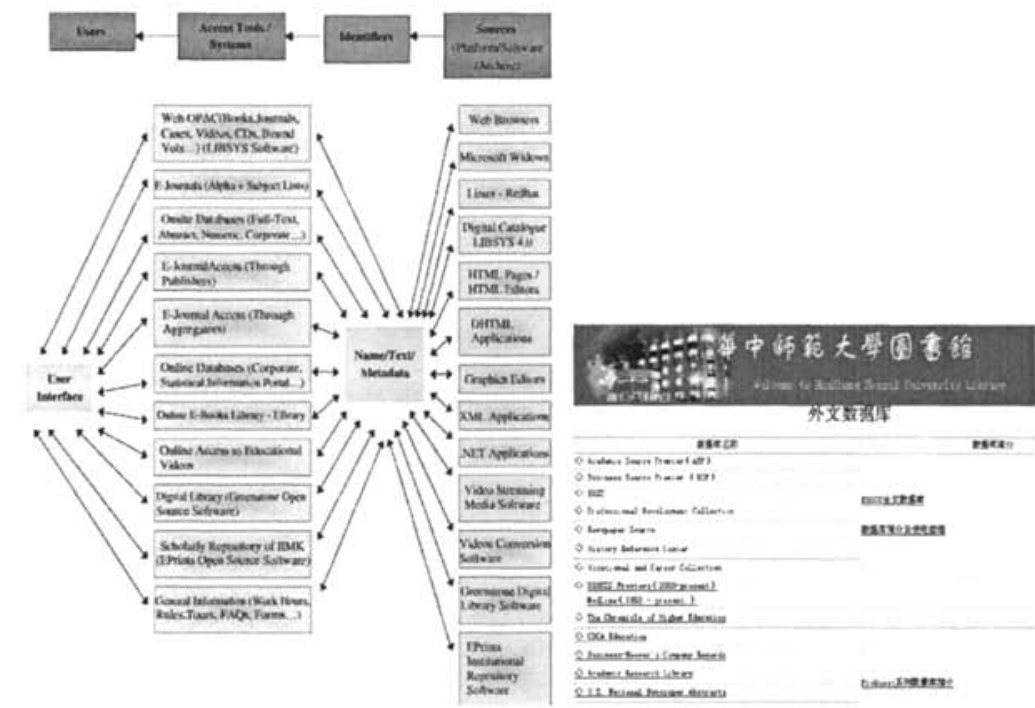

Fig2. Content/information integration model of DL portal

Fig3. Library Portal interface frame of DL HNU

\section{References}

1. Claudia A. Perry Education for Digitization: How Do We Prepare?, Academic Librarianship, Vol: 31( 6), 523-532 (2005)

2. Peter Hernon Candy Schwartz, Library education and its accrediting body: An opportunity for partnerships, Library \& Information Science Research, Vol:26 , 1-4 (2004)

3. Jane T. Bradford, Barbara Costello, and Robert Lenholt, Reference Service in the Digital Age: An Analysis of Sources Used to Answer Reference Questions, Academic Librarianship Available online 21 April, 263-272 (2005)

4. Jane M. Kathman and Michael D. Kathman, Training Student Employees for Quality Service, Academic Librarianship, Vol:26,(3), 176-182 (2004)

5 Natalia Donchenkoa,Irina Kerzumb, Between slump and hope: Library and information science education in Russia The International Information \& Library Review The International Information \& Library Review 38, 181-184 (2006) 